\title{
Robotic pelvic lymph node dissection for rectal cancer
}

\author{
P. Tejedor ${ }^{1}$ - F. Sagias ${ }^{1}$ A. Ahmed ${ }^{1}$ - S. Naqvi ${ }^{1}$ - J. S. Khan ${ }^{1}$ \\ Received: 6 October 2018 / Accepted: 26 October 2018 / Published online: 14 November 2018 \\ (c) The Author(s) 2018
}

Keywords Robotic Surgical Procedures $\cdot$ Lymph Node Excision $\cdot$ Minimally invasive surgery $\cdot$ Colorectal Neoplasms

Lateral lymph nodes are involved approximately in 10-25\% of patients with rectal cancer [1]; however, routine lateral pelvic lymph node dissection (LPLND) has not been shown to improve 5-year overall or disease-free survival [2]. Whilst in Japan, it is indicated for patients with T3-T4 rectal cancers [1], in Europe chemoradiotherapy is the modality of choice for treating lateral pelvic nodes. Lateral pelvic lymph node dissection is not a routine practice in most surgical centres in Europe. There is a belief that metastasis to lateral nodes suggest systemic disease and hence should be treated with chemoradiation. However, in selected patients the use of pelvic radiotherapy can be avoided by offering surgical excision of lateral nodes [3].

Robotic LPLND has demonstrated non-inferiority results versus laparoscopic LPLND, with lower rates of positive resection margins and higher 5-year disease-free survival [4]. Moreover, this technique offers better exposure and clearer visualization of the dissection plane and the surrounding structures. It allows the surgeon to perform a more accurate dissection reducing the risk of complications. The technique is shown in the attached video.

The patient was a 65 -year-old male with a body mass index of $28 \mathrm{~kg} / \mathrm{m}^{2}$. He had a robotic total mesorectal excision (TME) for a rectal cancer located $3 \mathrm{~cm}$ from the anorectal margin. Preoperative computed tomography scan showed suspicious left pelvic sidewall nodes (T3aN1). There was uptake on positron emission tomography scan in the left pelvic sidewall nodes (Fig. 1).

The TME was performed according to the single docking technique [5]. Port placement is represented in Fig. 2.

Electronic supplementary material The online version of this article (https://doi.org/10.1007/s10151-018-1873-3) contains supplementary material, which is available to authorized users.

J. S. Khan

jim.khan@porthosp.nhs.uk

1 Queen Alexandra Hospital, Portsmouth, UK
Once the TME was completed, LPLND commenced. The first step was an incision alongside the medial umbilical fold and extending up to the common iliac artery. The left ureter and hypogastric nerve were identified early. Lymph nodes were dissected from the bifurcation of the common iliac artery downwards. The external iliac artery and vein were exposed and the lymph nodes were resected from the external iliac vessels (Fig. 3). The internal iliac vessels were then identified and cleared of lymphatic tissue (Fig. 4). Dissection was continued into the obturator fossa where the obturator nerve was identified medial to the external iliac vein and lateral to the superior vesical artery (Fig. 5), which was preserved. Attention was focussed on the internal iliac artery and the anterior division was dissected to expose the superior and inferior vesical, obturator and umbilical arteries. The lymph node mass was excised en bloc and retrieved in a bag. The robotic cart and arm setup was the same as for TME and other adjustments were made. Monopolar scissors, fenestrated bipolar grasper and a double fenestrated grasper were used for dissection.

Total operative time was $420 \mathrm{~min}$, including $100 \mathrm{~min}$ for the LPLND. There was no injury to the surrounding tissues. The patient was discharged on the 7th postoperative day without any complications. Pathological findings were ypT2N0.

LPLND is a technically challenging procedure. Lymphadenectomy in a narrow pelvis amongst all the critical structures can be facilitated with the use of a robotic platform with enhanced vision and EndoWrist ${ }^{\circledR}$ instruments. There is a potential risk of serious complications and hence this procedure should not be attempted without proper training and mentoring. 


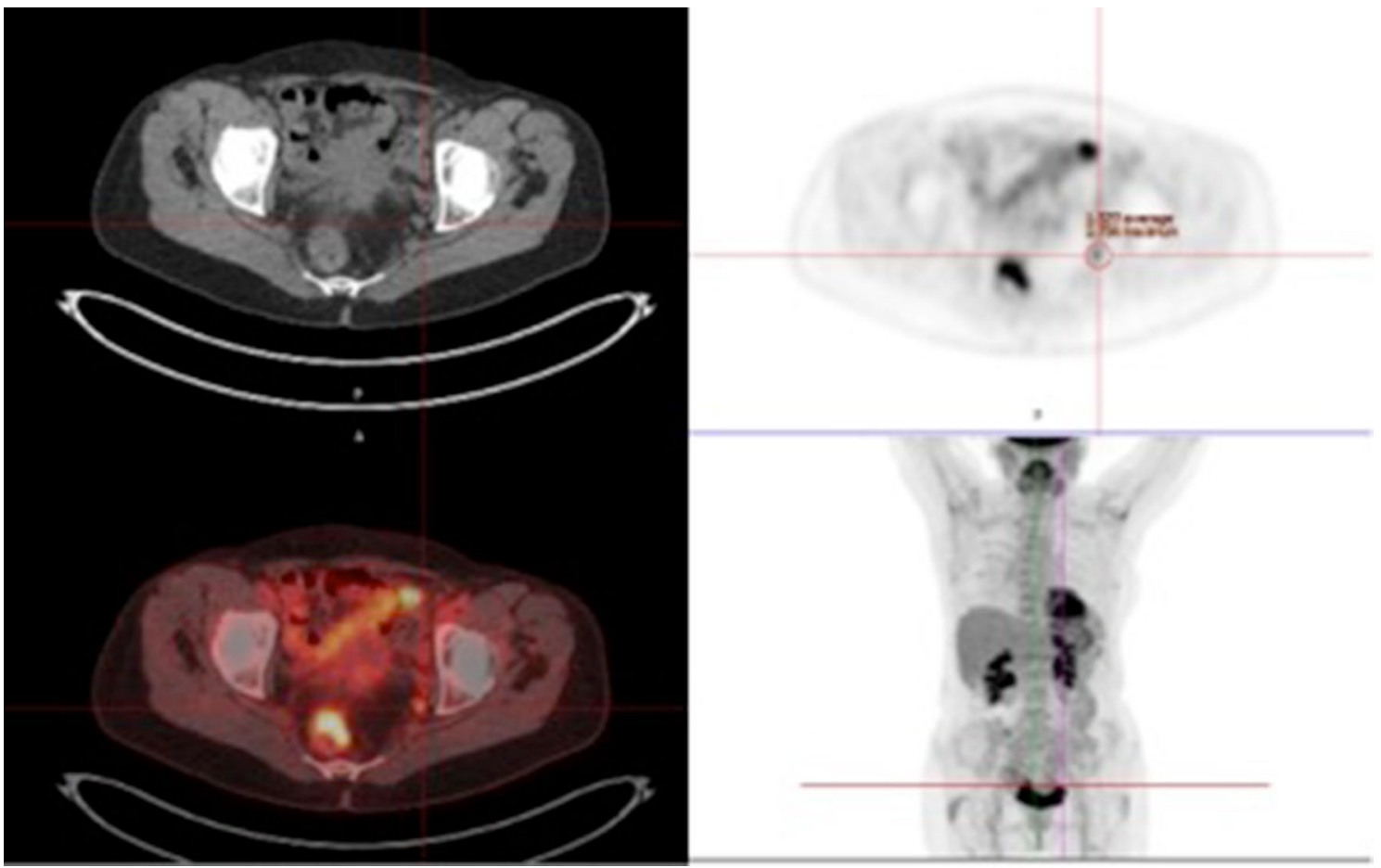

Fig. 1 Positron emission tomography scan showing nodes in the left pelvic sidewall (yellow arrow)

A
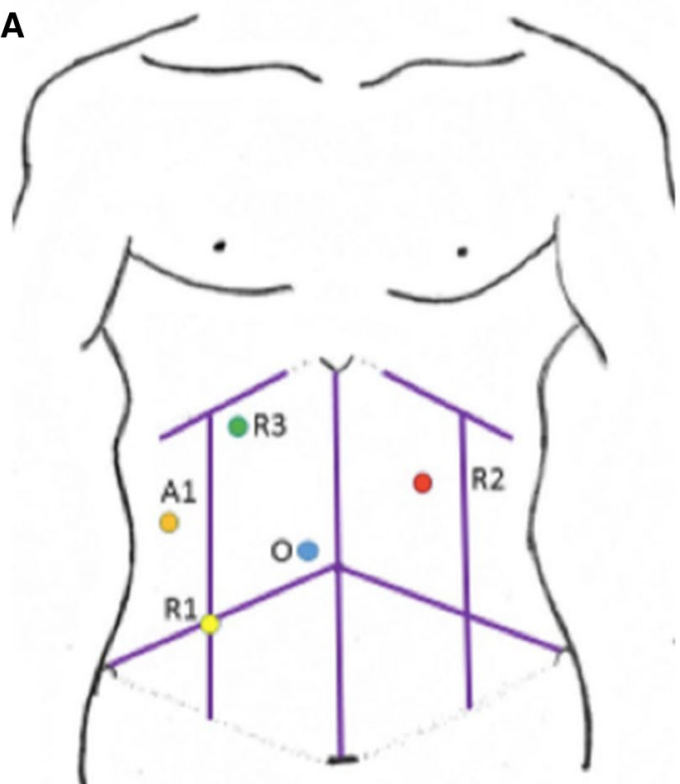

B

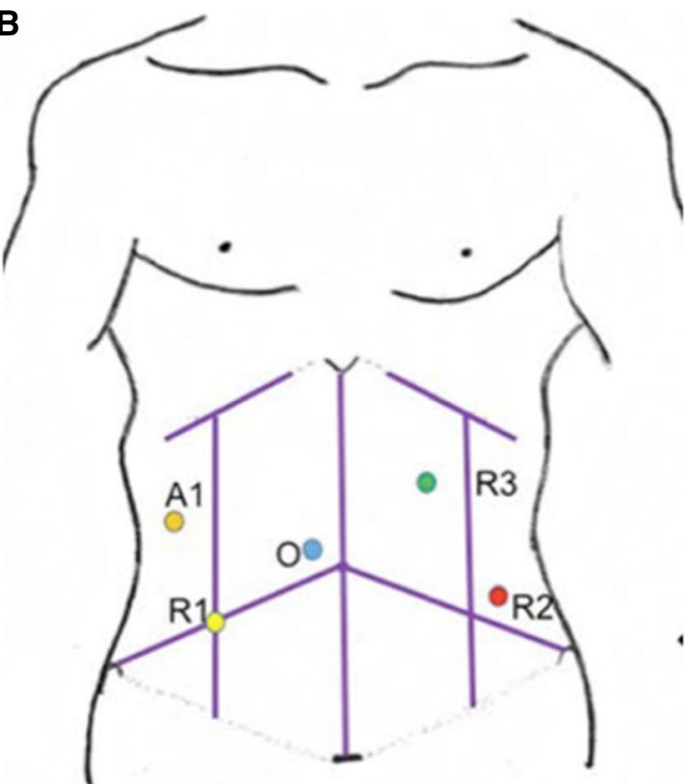

Fig. 2 a Initial configuration of the ports at the start of the procedure. b Port positioning during the total mesorectal excision phase. Rl first robotic port, $R 2$ second robotic port, $R 3$ third robotic port, $A 1$ assistant port, $O$ optical port 


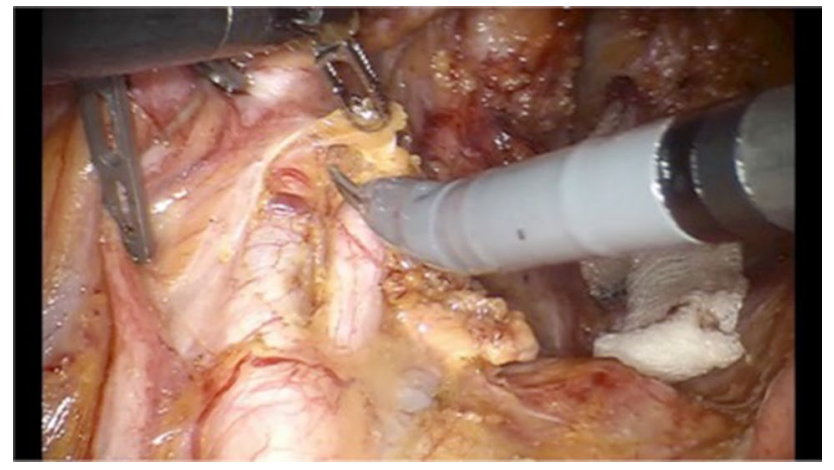

Fig. 3 Intraoperative views during a robotic lateral pelvic node dissection. Dissection of lymph nodes around the external iliac vessels

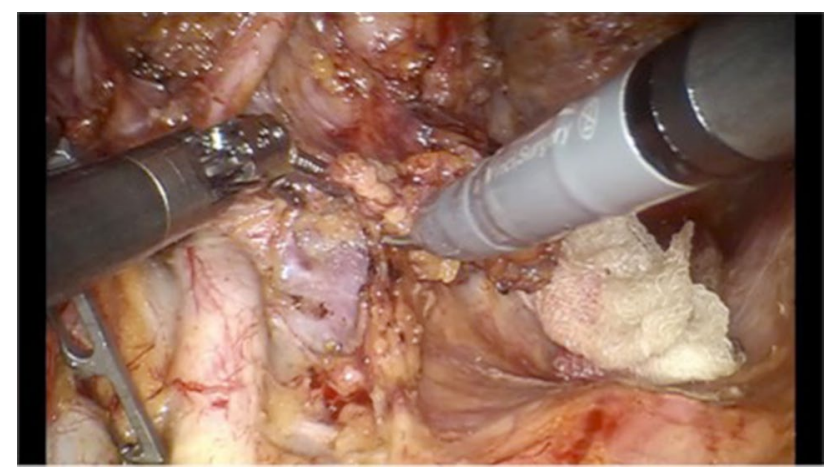

Fig. 4 Intraoperative views during a robotic lateral pelvic node dissection. Dissection of lymph nodes around the internal iliac vessels

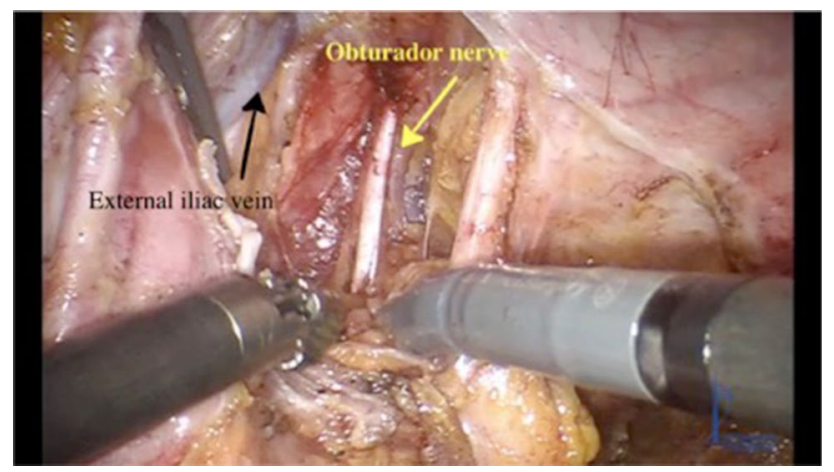

Fig. 5 Intraoperative views during a robotic lateral pelvic node dissection. Isolation of the obturator nerve
Funding No funding.

\section{Compliance with ethical standards}

Conflict of interest Authors have no conflict of interest.

Ethical approval All procedures performed in studies involving humans were in accordance with ethical standards of the institutional research committee and the 1964 Helsinki declaration and its later amendments.

Informed consent Informed consent was obtained from all participants.

Open Access This article is distributed under the terms of the Creative Commons Attribution 4.0 International License (http://creativeco mmons.org/licenses/by/4.0/), which permits unrestricted use, distribution, and reproduction in any medium, provided you give appropriate credit to the original author(s) and the source, provide a link to the Creative Commons license, and indicate if changes were made.

\section{References}

1. Watanabe T, Muro K, Ajioka Y, Hashiguchi Y, Ito Y, Saito Y, Hamaguchi T, Ishida H, Ishiguro M, Ishihara S, Kanemitsu Y, Kawano H, Kinugasa Y, Kokudo N, Murofushi K, Nakajima T, Oka S, Sakai Y, Tsuji A, Uehara K, Ueno H, Yamazaki K, Yoshida M, Yoshino T, Boku N, Fujimori T, Itabashi M, Koinuma N, Morita T, Nishimura G, Sakata Y, Shimada Y, Takahashi K, Tanaka S, Tsuruta O, Yamaguchi T, Yamaguchi N, Tanaka T, Kotake K, Sugihara K (2018) Japanese Society for Cancer of the Colon and Rectum (JSCCR) guidelines 2016 for the treatment of colorectal cancer. Int J Clin Oncol 23(1):1-34. https://doi. org/10.1007/s10147-017-1101-6

2. Georgiou P, Tan E, Gouvas N, Antoniou A, Brown G, Nicholls RJ, Tekkis P (2009) Extended lymphadenectomy versus conventional surgery for rectal cancer: a meta-analysis. Lancet Oncol 10(11):1053-1062. https://doi.org/10.1016/s1470-2045(09)70224 $-4$

3. Yano H, Moran BJ (2008) The incidence of lateral pelvic side-wall nodal involvement in low rectal cancer may be similar in Japan and the West. Br J Surg 95(1):33-49. https://doi.org/10.1002/ bjs. 6061

4. Kim HJ, Choi GS, Park JS, Park SY, Lee HJ, Woo IT, Park IK (2018) Selective lateral pelvic lymph node dissection: a comparative study of the robotic versus laparoscopic approach. Surgical Endosc 32(5):2466-2473. https://doi.org/10.1007/s0046 4-017-5948-4

5. Ahmed J, Siddiqi N, Khan L, Kuzu A, Parvaiz A (2016) Standardized technique for single-docking robotic rectal surgery. Colorectal Dis 18(10):O380-Oo384. https://doi.org/10.1111/codi.13466 